\title{
Vascular Endothelial Growth Factor and Transforming Growth Factor- $\beta 1$ Are Highly Expressed in the Cerebrospinal Fluid of Premature Infants with Posthemorrhagic Hydrocephalus
}

\author{
AXEL HEEP, BIRGIT STOFFEL-WAGNER, PETER BARTMANN, SUSANNE BENSELER, \\ CARLO SCHALLER, PETER GRONECK, MICHAEL OBLADEN, AND \\ URSULA FELDERHOFF-MUESER \\ Department of Neonatology [A.H., P.B., S.B.], University of Bonn, D-53113 Bonn, Germany; Department \\ of Clinical Biochemistry [B.S.-W.], University of Bonn, D-53105 Bonn, Germany; Department of \\ Neurosurgery [C.S.], University of Bonn, D-53105 Bonn, Germany; Department of Neonatology [P.G.], \\ Cologne Children Hospital, D-50735 Cologne, Germany; and Department of Neonatology [M.O., \\ U.F.-M], Charité, Campus Virchow, University Medical Center Berlin, D-13353 Berlin, Germany
}

\begin{abstract}
The expression of specific growth factors such as vascular endothelial growth factor (VEGF) and transforming growth factor- $\beta 1$ (TGF- $\beta 1$ ) is of importance during brain development and in the pathogenesis of neurodegenerative disorders. VEGF and TGF- $\beta 1$ was studied in the cerebrospinal fluid (CSF) of neonates with posthemorrhagic hydrocephalus (PHHC) and nonhemorrhagic hydrocephalus. For determining the interference of inflammatory cytokine interaction with the expression of VEGF and TGF- $\beta 1$, IL- 6 and IL-10 CSF concentrations were measured. Eighteen neonates who had PHHC and underwent serial reservoir puncture and nine neonates who had congenital nonhemorrhagic hydrocephalus $(\mathrm{CHC})$ and underwent first shunt surgery were included in the study. CSF samples of 11 neonates with lumbar puncture for the exclusion of meningitis served as control subjects. VEGF, TGF- $\beta 1$, IL- 6 , and IL-10 concentrations in the CSF were measured by ELISA technique. VEGF concentrations in the CSF of patients with PHHC were significantly higher (median: $377 \mathrm{pg} / \mathrm{mL}$; range: 101-1301 pg/mL) when compared with patients with $\mathrm{CHC}$ (median: $66 \mathrm{pg} / \mathrm{mL}$; range: 3-1991; $p<$ 0.001 ) and control subjects (median: $2 \mathrm{pg} / \mathrm{mL}$; range: $0-12$
\end{abstract}

\section{ABSTRACT}

$\mathrm{pg} / \mathrm{mL} ; p<0.0001)$. TGF- $\beta 1$ CSF concentrations did not differ from control infants in all groups. Median IL-6 and IL-10 concentrations in the CSF were found to be low in all patient groups. Increased release of VEGF in the CSF of neonates with PHHC and nonhemorrhagic hydrocephalus may serve as an indicator of brain injury from progressive ventricular dilation. TGF- $\beta 1$ CSF concentrations are not elevated in the phase of acute fibroproliferative reactions in patients with PHHC. (Pediatr Res 56: 768-774, 2004)
Abbreviations
CHC, congenital hydrocephalus
CSF, cerebrospinal fluid
ICH, intracerebral hemorrhage
ICP, intracerebral pressure
IVH, intraventricular hemorrhage
PHHC, posthemorrhagic hydrocephalus
TGF- $\boldsymbol{\beta} 1$, transforming growth factor- $\beta 1$
VEGF, vascular endothelial growth factor
WMD, white matter disease

The expression of specific growth factors such as vascular endothelial growth factor (VEGF) and transforming growth factor- $\beta 1$ (TGF- $\beta 1$ ) plays a pivotal role during a variety of normal or pathologic processes, including tissue repair $(1,2)$,

Received January 29, 2004; accepted June 1, 2004.

Correspondence: Axel Heep, M.D., Department of Neonatology, University of Bonn, Adenauerallee 119, D-53113 Bonn, Germany; e-mail: a.heep@uni-bonn.de

This study was supported by BMBF grant Z 01ZZ0101.

DOI: 10.1203/01.PDR.0000141524.32142.53 embryonic development (3), and tumor genesis (4). VEGF is expressed from endothelial cells. It increases peripheral oxygen delivery by promoting angiogenesis, involving endothelial cell migration, proliferation, and differentiation, as well as proteolysis of extracellular matrix $(4,5)$. Expression of VEGF after acute hypoxia is highly sensitive (6). TGF- $\beta 1$ is expressed from endothelial, hematopoietic, and connective tissue cells $(7,8)$. It plays an important role in the regulation of tissue proliferation, embryonic development, wound healing, and 
angiogenesis $(1,2)$. Mutations of the TGF $\beta$ gene family result in disturbed intracellular signaling associated with diseases such as cancer and hereditary hemorrhagic telangiectasis (7).

An imbalance of tissue repair and fibroproliferatory reactions characterizes the neuropathology of posthemorrhagic hydrocephalus (PHHC) after severe intraventricular hemorrhage (IVH) in preterm infants. The development of arachnoidal fibrosis ultimately causes cerebrospinal fluid (CSF) malabsorption $(9,10)$ and thereby increased intracranial pressure (ICP) (11). The activation of extracellular matrix protein biosynthesis, measured as the persisting elevation of the propeptides of type I and III procollagen, was found in the CSF of patients who ultimately developed PHHC 3-4 wk after IVH $(12,13)$. CSF concentrations of proinflammatory IL-6 and antiinflammatory IL-10 were measured to illustrate a possible interference of inflammatory cytokine interaction with the expression of VEGF and TGF- $\beta 1$. Sonographic cystic white matter disease (c-WMD) was defined as a secondary outcome parameter to correlate the expression of VEGF and TGF- $\beta 1$, with gross white matter damage $(11,14)$ and reorganization after severe brain injury.

The aim of this study was to investigate the expression of VEGF and TGF- $\beta 1$ in the CSF of premature infants with PHHC and in neonates with nonhemorrhagic hydrocephalus. Infants without neurologic disease or signs of increased intracranial pressure served as control subjects. We hypothesized that the expression of VEGF and TGF- $\beta 1$ in the CSF in patients with PHHC may correlate with the enhanced tissue repair and fibroproliferatory reactions. To analyze the confounding effect of elevated ICP on growth factor expression, age-matched groups of neonates with nonhemorrhagic congenital hydrocephalus and neonates with exclusion of neurologic morbidity were included in the study.

\section{METHODS}

Patient selection. CSF was obtained prospectively from three groups of newborn infants who were admitted to the three study centers between March 1999 and October 2001. Group A consisted of premature infants $<32$ wk gestational age with PHHC. Group B consisted of newborn infants with congenital nonhemorrhagic hydrocephalus. Group $\mathrm{C}$ consisted of newborn infants who underwent lumbar puncture for sepsis workup (Table 1).

Group A: premature infants with progressive $\mathrm{PHHC}$. Thirty-five ventricular CSF samples were obtained from 18 premature infants who were admitted for surgical treatment of PHHC after severe IVH. The median birth weight was $676 \mathrm{~g}$, and the median gestational age at birth was $25 \mathrm{wk}+0 \mathrm{~d}$. In all patients, ultrasound revealed severe IVH. Ultrasound findings of IVH were classified according to the criteria by Volpe (11): 1) grade I (mild), germinal matrix hemorrhage with no or minimal IVH; 2) grade II (moderate), IVH (10-50\% of ventricular area in parasagittal scan); 3) grade III (severe), ( $>50 \%$ of ventricular area in parasagittal scan); 4) apparent periventricular hemorrhagic infarction. Severe IVH was defined as either grade III IVH or IVH with apparent periventricular hemorrhagic infarction.

Nine of the 18 patients had signs of gross c-WMD on ultrasound at day 28 postnatal age (Table 2). WMD was defined as single or multiple cystic periventricular leukomalacia or gross cystic white matter defect after hemorrhagic infarction of the periventricular white matter (14). In all patients, ventricular dilation and increased ICP were present as confirmed by physical examination and ultrasound.

CSF drainage by surgical ventriculostomy and implantation of a ventriculostomy catheter reservoir was performed after a median of $27 \mathrm{~d}$ (range: 14-75) after IVH (Table 3). The intervention was performed when at least one of the following criteria was met: 1) signs of IVH and progressive ventricular dilation identified by ultrasound (ventricular width $>97 \%$ percentile) (15) and progressive enlargement of head circumference ( $>2 \mathrm{~cm} / \mathrm{wk}$, daily measurement), 2) bulging fontanel with widening of the sagittal suture, and 3) clinical signs of increased ICP (seizures, apnea-bradycardia, and hypoventilation) $(11,16)$.

The ventriculostomy catheter reservoirs were subsequently tapped two to three times a day using a sterile technique and a 27-G butterfly needle. CSF was withdrawn over a period of 2-5 min. The CSF volume taken was estimated by ultrasound, ICP measurement, or clinical evaluation (16). All patients required shunt surgery for symptomatic PHHC.

Two CSF samples were taken from each patient for analysis. The first study sample was taken after the implantation of a Rickham reservoir system, depending on clinical criteria of elevated ICP with therapeutic intention. The second study sample was taken at the time of permanent shunt placement (median: 62 d postnatal age; range: 40-120) when CSF protein content was $<200 \mathrm{mg} / \mathrm{dL}$ (median; Table 3 ).

Fourteen ICP measurements could be obtained from six infants of group A during CSF reservoir puncture. ICP was measured in $\mathrm{cm} \mathrm{H}_{2} \mathrm{O}$ [normal: $40-50 \mathrm{~cm} \mathrm{H}_{2} \mathrm{O}$; (11)] via a tube connected to the butterfly puncture needle before and after

Table 1. Clinical data of the study population

\begin{tabular}{lccc}
\hline \multicolumn{1}{c}{ Characteristic } & Group A $(n=18)$ & Group B $(n=9)$ & Group C $(n=11)$ \\
\hline Gestational age* $($ wk $+\mathrm{d})$ & $25+0(22+5$ to $30+4) \dagger$ & $34+3(30+1$ to $38+4) \ddagger$ & $33+4(27+0$ to $40+2)$ \\
Birth weight* $(\mathrm{g})$ & $676(470-1685) \dagger$ & $2750(1640-3900) \ddagger$ & $2230(790-3450)$ \\
Severe IVH $[n(\%)]$ & $18(100)$ & 0 & 0 \\
Cystic WMD $[n(\%)]$ & $9(50)$ & 0 & 0 \\
\hline
\end{tabular}

Study population divided into three groups. Group A, neonates with PHHC $(n=18)$; group B, neonates with congenital nonhemorrhagic hydrocephalus $(n=$ 9); group C, neonates; CSF taken at sepsis workup for exclusion of meningitis $(n=11)$.

* Values are median and range.

$\dagger p=0.0001$ group A vs groups B/C.

$\ddagger p=$ NS group B $v s$ group C. 
Table 2. Ultrasound findings in WMD patients

IVH

\begin{tabular}{|c|c|c|}
\hline Patient & (left/right) & Localization of cystic defects on ultrasound \\
\hline 1 & $\mathrm{IV} / \mathrm{II}$ & $\begin{array}{l}\text { Large cystic parietal periventricular white matter } \\
\text { defect on the left }\end{array}$ \\
\hline 2 & $\mathrm{IV} / 0$ & Multiple frontal white matter cysts on the left \\
\hline 3 & I/III & Frontal white matter cyst on the right \\
\hline 4 & IV/IV & Frontal white matter cyst on the right \\
\hline 5 & III/IV & Bilateral frontal white matter cysts \\
\hline 6 & IV/- & $\begin{array}{l}\text { Large cystic periventricular white matter defect on } \\
\text { the left }\end{array}$ \\
\hline 7 & IV/II & Bilateral multiple frontal cystic lesions \\
\hline 8 & II/IV & $\begin{array}{l}\text { Large hemorrhagic infarct in the frontal and } \\
\text { parietal periventricular white matter on the right }\end{array}$ \\
\hline 9 & IV/III & $\begin{array}{l}\text { Large hemorrhagic infarct in the frontal white } \\
\text { matter on the left }\end{array}$ \\
\hline
\end{tabular}

Table 3. CSF drainage in patients with PHHC

\begin{tabular}{lr}
\hline \multicolumn{1}{c}{ Characteristic } & $(n=18)$ \\
\hline Age at ventriculostomy intervention (d*; CSF & $27(14-75)$ \\
sample 1) & $62(40-120)$ \\
Age at shunt placement (d; CSF sample 2) & $157(34-412)$ \\
Protein content of CSF at shunt placement (mg/dL) & \\
\hline
\end{tabular}

Figures are given as median and range.

* Days after diagnosis of severe IVH.

tapping. In the remaining infants, this procedure was impossible to perform during s.c. reservoir puncture as infants were not sedated. Spontaneous movements and crying may cause incorrect results. In addition, protein clotting can obstruct the manometry device (11).

Group B: newborn infants with congenital nonhemorrhagic hydrocephalus. Ventricular CSF samples were collected from nine patients (median birth weight: $2750 \mathrm{~g}$; gestational age at birth: $34 \mathrm{wk}+3 \mathrm{~d}$ ) at the time of first shunt implantation (median: $5 \mathrm{~d}$ postnatal age; range: $1-45$ ). Patients had hydrocephalus associated with Arnold Chiari II malformation $(n=1)$, aqueduct stenosis $(n=2)$, giant interhemispheric cyst hydrocephalus $(n=2)$, and congenital nonhemorrhagic hydrocephalus of unknown origin $(n=4)$. Hydrocephalus and increased ICP were confirmed by clinical criteria and ventricular enlargement on ultrasound in all patients.

Group C: newborn infants who underwent lumbar puncture for sepsis workup. Lumbar CSF samples were collected from 11 neonates (median birth weight: $2230 \mathrm{~g}$; gestational age at birth: $33 \mathrm{wk}+4 \mathrm{~d}$ ) for the exclusion of meningitis. None of the infants showed neurologic deficit on clinical examination. CSF leukocyte counts, total protein content, and bacterial cultures were obtained and remained within normal range. CSF was immediately centrifuged and stored at $-40^{\circ} \mathrm{C}$ until further analysis.

The study design strictly followed the approval of the ethical committee of the University of Bonn (no. 116/02). The study design included the analysis of anonymous excess material. All samples were stripped of identifiers before analysis. In accordance with the ethical guidelines, no parental consent was required.

VEGF, TGF- $\beta 1, I L-6$, and IL-10 assays. VEGF and TGF- $\beta 1$ concentrations were determined using a commercially available sandwich ELISA (R\&D Systems, Wiesbaden, Germany) according to the manufacturer's instructions. The sensitivity of the assay was $5 \mathrm{pg} / \mathrm{mL}$. The intra-assay coefficient of variation was $5.1 \%$ (mean: $225 \mathrm{pg} / \mathrm{mL}, n=20$ ); the interassay coefficient of variation was $6.2 \%$ (mean: $255 \mathrm{pg} / \mathrm{mL}, n=20$ ). VEGF and TGF- $\beta 1$ assays were carried out in duplicate.

IL- 6 and IL-10 were measured with a commercially available solid-phase enzyme-labeled chemiluminescent sequential immunometric assay on an Immulite analyzer (DPC Biermann, Bad Naunheim, Germany). The sensitivity of the assays were $2 \mathrm{pg} / \mathrm{mL}$ for IL-6 and $1 \mathrm{pg} / \mathrm{mL}$ for IL-10. The intra-assay coefficients of variation were $3.5 \%$ (mean: $88 \mathrm{pg} / \mathrm{mL}, n=40$ ) for IL-6 and 2.9\% (mean: $18 \mathrm{pg} / \mathrm{mL}, n=40$ ) for IL-10. The interassay coefficients of variation were $5.1 \%$ (mean: 112 $\mathrm{pg} / \mathrm{mL}, n=40$ ) for IL-6 and $4.8 \%$ (mean: $46 \mathrm{pg} / \mathrm{mL}, n=40$ ) for IL-10.

Total CSF protein concentrations were determined using a commercially available on a Dimension RxL analyser (Dade Behring, Schwalbach, Germany). In the reaction sequence, pyrogallol red combines with sodium molybdate to form a red complex with maximum absorbance at $470 \mathrm{~nm}$. The protein in the sample reacts with this complex in acid solution, which absorbs at $600 \mathrm{~nm}$. The absorbance at $600 \mathrm{~nm}$ is directly proportional to the concentration of protein in the sample. The sensitivity of the method was $20 \mathrm{mg} / \mathrm{L}$. The intra-assay coefficient of variation was $0.6 \%$ (mean: $204 \mathrm{mg} / \mathrm{L}, n=20$ ); the interassay coefficient of variation was $1.51 \%$ (mean: $209 \mathrm{mg} / \mathrm{L}$, $n=20)$.

Data analysis. For statistical analysis, the Mann-Whitney $U$ test was used with two-sided $p$ values to compare continuous nonparametric groups of values, as the distribution of values was non-Gaussian (Tables 1 and 4, Figs. 1 and 2). Comparison between proportions (CSF sample 1 versus CSF sample 2 in the PHHC group) were performed with the Wilcoxon test. Logistic regression models were used to investigate the regres-

Table 4. VEGF, TGF- $\beta 1, I L-6, I L-10$, and total protein concentrations in the CSF of the study population

\begin{tabular}{lcccccc}
\hline & $N$ & VEGF $(\mathrm{pg} / \mathrm{mL})$ & TGF- $\beta 1(\mathrm{pg} / \mathrm{mL})$ & IL-6 $(\mathrm{pg} / \mathrm{mL})$ & $\mathrm{IL}-10(\mathrm{pg} / \mathrm{mL})$ & Total CSF protein $(\mathrm{mg} / \mathrm{dL})$ \\
\hline Group A sample 1 & 18 & $377(101-1301)$ & $1504(298-2977)$ & $46(5-1402)$ & $7(5-543)$ & $198(61-693)$ \\
Group A sample 2 & 17 & $191(5-655)$ & $737(157-3060)$ & $21.5(5-1588)$ & $5(5-1588)$ & $157(34-412)$ \\
Group B & $9\left(5^{*}\right)$ & $66(5-1991)$ & $732(7-2594)$ & $13(5-91)$ & $5(5-6)$ & $107(52-526)$ \\
Group C & $11\left(1^{*}\right)$ & $5(5-12)$ & $1006(207-2999)$ & 5 & 5 & $64(32-118)$ \\
\hline
\end{tabular}

Study population divided into four groups. Group A sample 1, neonates with PHHC, sample at ventriculostomy $(n=18)$; group A sample 2, neonates with PHHC, sample at definite shunt placement; group B, neonates with congenital nonhemorrhagic hydrocephalus $(n=9)$; group C, neonates, CSF taken at sepsis workup for exclusion of meningitis $(n=11)$. Values are median and range.

* Number of analyzed probes for IL-6 and IL-10. 


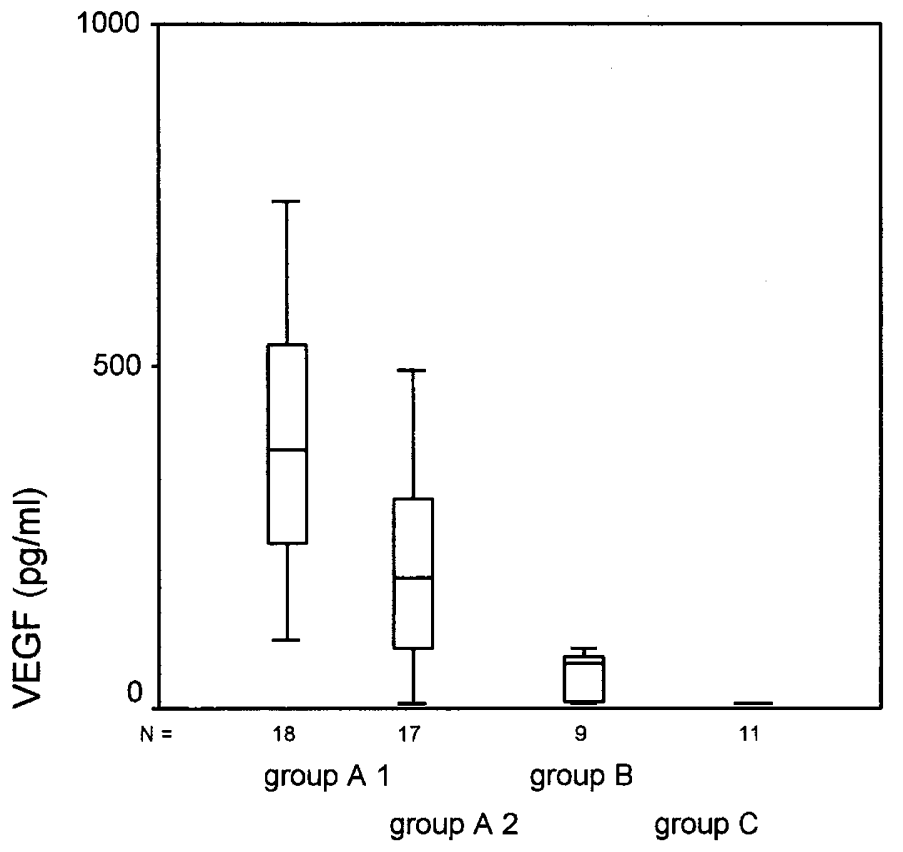

Study groups

Figure 1. VEGF concentrations in the CSF of the study groups. Group A sample 1: neonates with PHHC. Sample at ventriculostomy $(n=18)$. Group A sample 2: neonates with PHHC. Sample at definite shunt placement $(n=17)$. Group B: neonates with congenital nonhemorrhagic hydrocephalus $(n=9)$. Group C: neonates. CSF taken at sepsis workup for exclusion of meningitis $(n=11)$. Values are median and 25th and 75th percentiles (boxes) and 5th to 95th percentiles (whiskers). Group A1/group C, $p=$ 0.04; group A2/group C, $p=0.001$; groups A1/B, A2/B, B/C, $p=0.0001$ (Mann-Whitney $U$ test).

sion relationships between the occurrence of WMD and the CSF VEGF and TGF- $\beta 1$ values (Figs. 3 and 4). Statistical analyses were processed by the use of statistical software SPSS 10.7 (SPSS Inc., Chicago, IL).

\section{RESULTS}

VEGF concentrations of patients with PHHC (sample 1: median $377 \mathrm{pg} / \mathrm{mL}$, range $101-1301 \mathrm{pg} / \mathrm{mL}$; sample 2: median $191 \mathrm{pg} / \mathrm{mL}$, range $5-655 \mathrm{pg} / \mathrm{mL}$ ) were significantly elevated (sample 1: $p<0.04$; sample 2: $p<0.001$ ) compared with those of patients with congenital nonhemorrhagic hydrocephalus (median: $66 \mathrm{pg} / \mathrm{mL}$; range: $3-1991 \mathrm{pg} / \mathrm{mL}$ ). VEGF concentrations in the CSF of patients with PHHC were significantly higher compared with controls (median: $2 \mathrm{pg} / \mathrm{mL}$; range: $0-12 \mathrm{pg} / \mathrm{mL}$; sample 1: $p<0.0001$; sample 2: $p<0.0001$ ). VEGF concentrations in patients with nonhemorrhagic hydrocephalus were significantly elevated compared with control subjects $(p<0.0001$; Fig. 1$)$. TGF- $\beta 1$ concentrations in the CSF were a median of at least 140 -fold increased above the detection limit in all samples but without significant difference in all study groups (Fig. 2).

CSF IL-6 concentrations all were above the detection limit in the study group. No significant differences within the study groups were found (Table 4). IL-10 CSF concentrations were significantly elevated in sample 1 of patients with PHHC

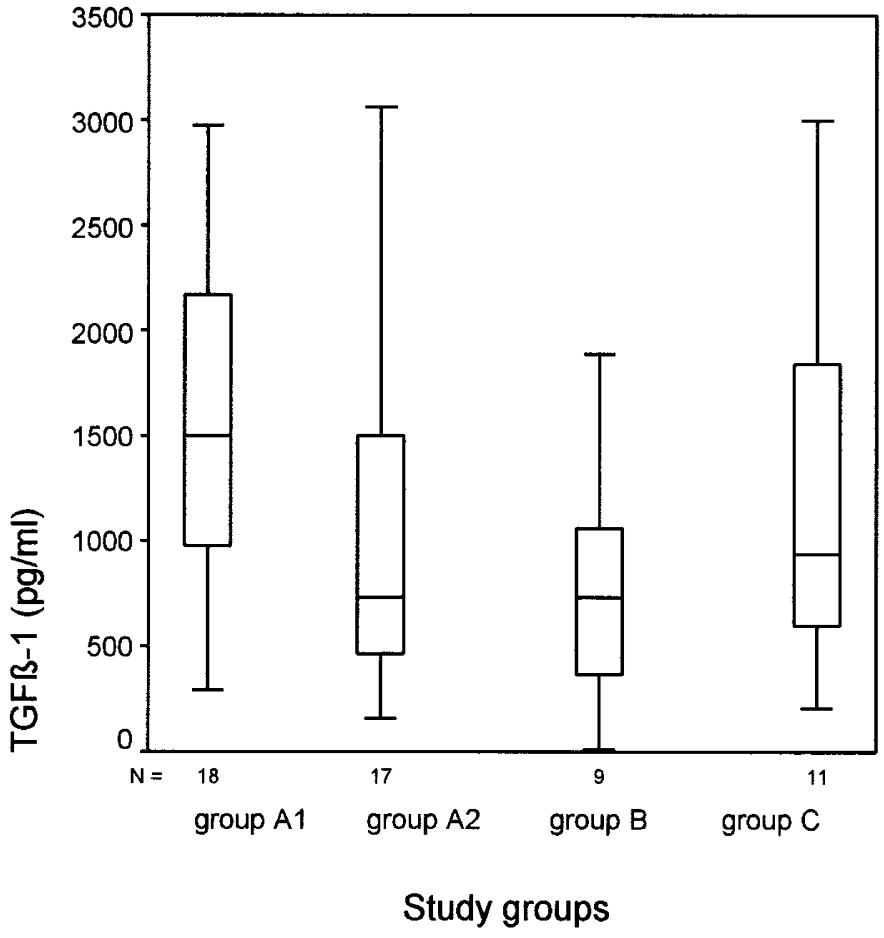

Figure 2. TGF- $\beta 1$ concentrations in the CSF of the study population. Group A sample 1: neonates with PHHC. Sample at ventriculostomy $(n=18)$. Group A sample 2: neonates with PHHC. Sample at definite shunt placement $(n=$ 17). Group B: neonates with congenital nonhemorrhagic hydrocephalus $(n=$ 9). Group C: neonates. CSF taken at sepsis workup for exclusion of meningitis $(n=11)$. Values are median and 25th and 75 th percentiles (boxes) and 5 th to 95th percentiles (whiskers). No significant differences within the groups (Mann-Whitney $U$ test).

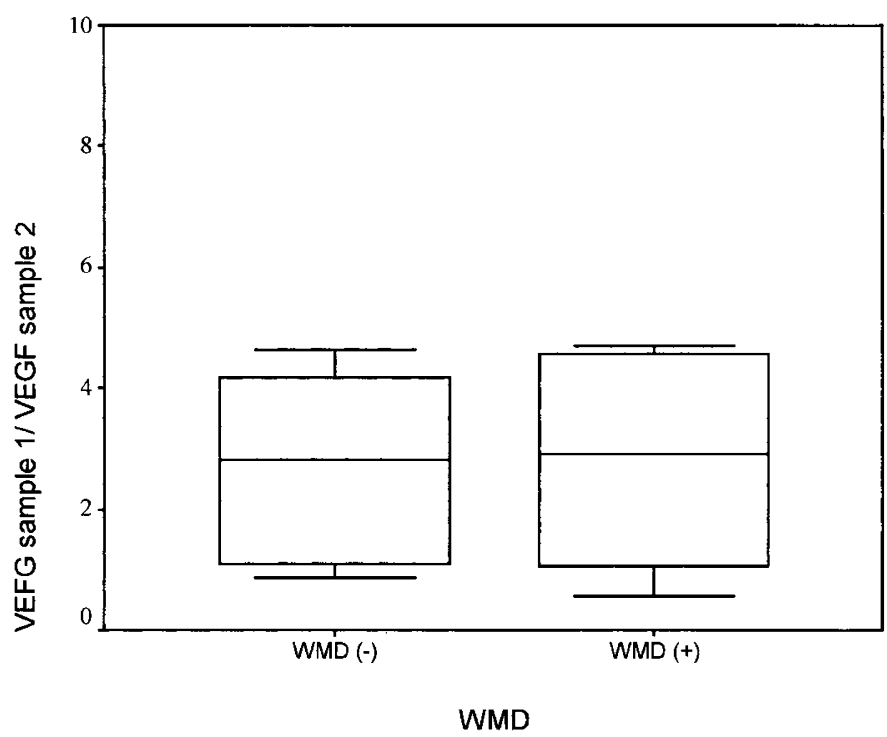

Figure 3. VEGF concentrations in the CSF of patients with PHHC. Logistic regression model correlating VEGF CSF concentration (sample 1/sample 2) with the occurrence of WMD ( $p=0.51$; odds ratio: 0.98 ; regression coefficient: -0.015 ). Values are median and 25 th and 75 th percentiles (boxes) and 5th to 95 th percentiles (whiskers).

compared with sample $2(p<0.034)$ and compared with patients with nonhemorrhagic hydrocephalus $(p<0.046)$. A limited number of samples from group $C$ could be analyzed for 


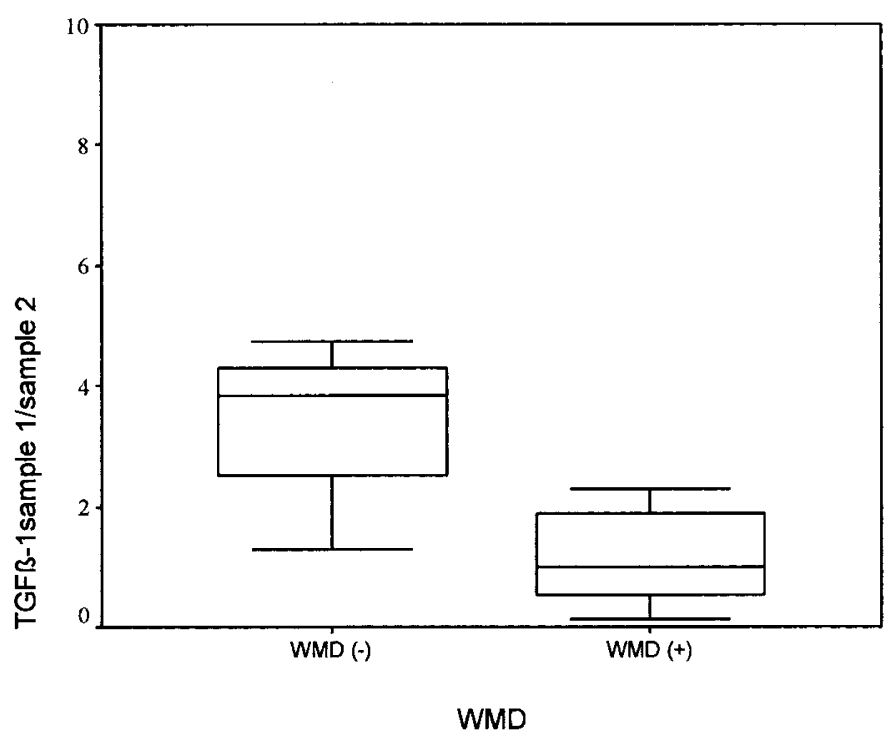

Figure 4. TGF- $\beta 1$ concentrations in the CSF of patients with PHHC. Logistic regression model correlating TGF- $\beta 1$ CSF concentration (sample 1 /sample 2 ) with the occurrence of WMD. $(p=0.047$; odds ratio: 0.35 ; regression coefficient: -1.06 ). Values are median and 25 th and 75 th percentiles (boxes) and 5th to 95th percentiles (whiskers).

IL-6 and IL-10 CSF concentrations (Table 4). Therefore, no statistics were performed on IL- 6 and IL-10 of group C compared with the other groups.

Total protein concentrations were found to be within the normal range for nonhemorrhagic hydrocephalus patients and for control subjects (Table 4). Total protein was significantly elevated in PHHC samples compared with controls $(p<0.002$ and $p<0.025$, sample 1 and sample 2; Table 4).

To investigate the relationships between the occurrence of WMD and the VEGF and TGF- $\beta 1$ CSF concentrations in the patients with PHHC, we used Wilcoxon test and logistic regression models. No significant correlation between VEGF CSF concentrations and the occurrence of WMD were observed within the group of patients with PHHC (Fig. 3). Wilcoxon test showed no significant differences for TGF- $\beta 1$ CSF concentrations within sample 1 and sample 2 of patients with PHHC $(p=0.13)$. The quotient sample $1 /$ sample 2 was used in the regression models. The logistic regression model showed a correlation between persisting high TGF- $\beta 1$ values and the occurrence of WMD $(p=0.047$; odds ratio: 0.35 ; regression coefficient: -1.06 ; Fig. 4).

\section{DISCUSSION}

A complex, balanced intracellular interaction through cellular secretion of different growth factors and specific cellsurface receptor activity is obligatory to maintain homeostasis in human tissue (7). VEGF and TGF- $\beta 1$ are members of the polypeptide growth factor family that mediate angiogenesis $(7,17)$ and regulate proliferation and differentiation (7) of cells. We studied VEGF, TGF- $\beta 1$, IL- 6 , and IL-10 concentrations in the CSF of premature infants to investigate the expression of growth factors in the situation of a potential imbalance in tissue repair leading to arachnoid fibrosis, CSF malabsorption, and increased ICP, correlating with manifestation of PHHC. Sev- eral experimental and clinical studies have indicated a role for specific growth factors mediating the course of neurodegenerative diseases such as subarachnoid hemorrhage $(18,19)$, ischemic encephalopathy (20), stroke (21), multiple sclerosis (1), and Alzheimer's disease $(22,23)$.

In a rat retina model of proliferative neovascularization, VEGF expression increases within 6-12 $\mathrm{h}$ after ischemia and remains elevated until neovascularization takes place $(4,6)$. In a retinal ganglion cell model of the rat, VEGF expression promotes neuronal regrowth and seems to have neuroprotective properties (24). Data from adult patients with acute stroke demonstrate a correlation between degree of stroke and expression of serum VEGF (21).

VEGF plays an important role during human brain development: immunohistochemistry revealed VEGF expression in the endothelial cells of cortex, leptomeninges, and subependymal layer (3), and expression was increased during brain maturation. In brains with signs of periventricular leukomalacia, VEGF was expressed in both astrocytes and endothelial cells that composed neovascularization around foci of necrosis (3). Chronically elevated ICP of patients with hydrocephalus may be related to chronic hypoxia. Elevated concentrations of VEGF were found in the CSF of pediatric patients with congenital hydrocephalus and posthemorrhagic hydrocephalus (25). This study was the first to indicate a coincidence of CSF infection and high expression of VEGF.

Our results demonstrate elevated VEGF CSF concentrations in both groups of patients with increased ICP (group A and group B) compared with VEGF CSF concentrations in patients with normal ICP (group C). These findings support the assumption of a correlation between increased intracranial pressure associated with chronic tissue hypoxia and VEGF expression in neonatal hydrocephalus. VEGF values were significantly higher in the PHHC group in comparison with congenital hydrocephalus, possibly indicating involvement in tissue repair and neovascularization after severe IVH in patients with PHHC.

Elevated VEGF concentrations 3-5 wk after brain injury were not coincident with gross white matter damage. When stratifying the PHHC samples to correlate VEGF concentrations and the occurrence of c-WMD, no differences were found between groups. The different extent of WMD (Table 2) and the variety of pathophysiologic mechanisms leading to these lesions makes the interpretation of the results difficult. Thus, a larger cohort study is needed.

In a study of patients with acute stroke, serum VEGF expression measurement correlated with infarct volume with a maximum peak at $1 \mathrm{wk}$ after the insult (21). Assuming a comparability in the pathogenesis of WMD after stroke in adult and neonatal WMD (26) and despite the different VEGF source (serum versus CSF), the difference in the results may be explained by a better correlation of early enhanced VEGF expression after hypoxic insult with the extent of parenchymal lesions.

TGF- $\beta 1$ is a member of the polypeptide growth factor family. The role of TGF- $\beta 1$ in neurodevelopment and neuroregeneration was demonstrated in animal models and in human disease. After intraventricular administration of TGF- $\beta 1$ in a 
mouse model, histopathology demonstrates meningeal changes with increased cellularity and arachnoid fibrosis leading to narrowing of the intrameningeal space and decreased CSF flow dynamics $(27,28)$. Increased TGF- $\beta 1$ concentrations in the CSF of patients with chronic inflammatory encephalitis, amyotrophic lateral sclerosis (29), and multiple sclerosis (30) correlate with duration and severity of chronic inflammatory disease. In addition, it is assumed that TGF- $\beta 1$ is involved in neuroprotection by inhibition of apoptosis $(31,32)$.

One previous report described TGF- $\beta 1$ release in the CSF of premature infants with PHHC (33). In this study, different therapeutic interventions were applied to prevent PHHC. The difference in the control group as well as at least the small number of included patients makes it difficult to compare results.

In our study population, TGF- $\beta 1 \mathrm{CSF}$ concentrations did not differ within the groups. However, analysis within subgroups of PHHC patients with or without $\mathrm{c}-\mathrm{WMD}$ revealed a significant difference. TGF $\beta-1$ concentrations in the CSF of patients with PHHC and c-WMD (sample 1/sample 2) remained in the same range, whereas the difference in TGF- $\beta 1$ CSF concentrations (sample 1/sample 2) was larger in patients without c-WMD (Fig. 4). This finding is in agreement with other observations assuming extended TGF- $\beta 1$ expression in tissue repair after brain injury $(18,34)$.

IL-6 and IL-10 act in the inflammatory cascade of infectious and inflammatory disease of the nervous system. The induction of proinflammatory cytokine release in the brain after endotoxin (LPS) stimulation was demonstrated in vitro (35) as well as in the rat model $(36,37)$. Enhanced expression of IL-6 mRNA after hypoxia-ischemia in the animal model (38) and in the cerebral endothelium cell model (39) demonstrates its important role in the pathogenesis of the inflammatory cascade. Proinflammatory cytokine release has been reported in the newborn brain after asphyxia (40) and in ventriculitis in the premature infants $(41,42)$. In an experimental rat model of ICH, IL-6 up-regulation peaked $12 \mathrm{~h}$ after ICH and was related to glial activation (43). Early increase of IL-6 and IL-10 CSF concentrations after ICH (44) or severe traumatic brain injury $(34,45,46)$ indicate its important role in mediating inflammatory response. In our study population, IL-6 and IL-10 concentrations in the CSF were found to be in a low range in all patient groups. The significant difference between the IL-10 concentrations of the early PPHC sample versus the late sample/nonhemorrhagic hydrocephalus possibly indicates that anti-inflammatory responses can be observed early after the IVH.

The present study demonstrates VEGF up-regulation in the CSF of premature infants with PHHC. The release of the proinflammatory cytokine IL-6 does not interfere in VEGF expression in patients who develop PHHC at 3-6 wk after severe IVH. The significant elevation of VEGF in the CSF and persisting high TGF- $\beta 1$ expression during the development of c-WMD may be of prognostic value to indicate severity of the brain damage after IVH in premature infants.

Acknowledgments. We gratefully acknowledge the skilled technical assistance by Anne Thiel and Martina Schmidt and the statistical support by R. Fimmers.

\section{REFERENCES}

1. Roberts AB, Sporn MB, Assoian RK, Smith JM, Roche NS, Wakefiled LM, Heine UI, Liotta LA, Falanga V, Kehrl JH, Fauci AS 1986 Transforming growth factor type $\beta$ rapid induction of fibrosis and angiogenesis in vivo and stimulation of collagen formation in vitro. Proc Natl Acad Sci USA 83:4167-4171

2. Ignotz RA, Massague J 1986 Transforming growth factor $\beta$ stimulates the expression of fibronectin and collagen and their incorporation into the extracellular matrix. J Biol Chem 261:4337-4345

3. Arai Y, Deguchi K, Takashima S 1998 Vascular endothelial growth factor in brains with periventricular leukomalacia. Pediatr Neurol 19:45-49

4. Cheng SY, Nagane M, Huang HS, Cavenee WK 1997 Intracerebral tumor associated hemorrhage caused by overexpression of vascular endothelial growth factor isoforms VEGF 121 and VEGF 165 but not VEGF 189. Proc Natl Acad Sci USA 94:1208112087

5. Jones KL, Krous HF, Nadeau J, Blackbourne B, Zielke HR, Gozal D 2003 Vascular endothelial growth factor in the cerebrospinal fluid of infants who died of sudden infant death syndrome: evidence for antecedent hypoxia. Pediatrics 111:358-363

6. Pierce EA, Avery RL, Foley ED, Aiello LP, Smith LE 1995 Vascular endothelial growth factor/vascular permeability factor expression in a mouse model of retinal neovascularization. Proc Natl Acad Sci USA 31:905-909

7. Blobe GC, Schiemann WP, Lodish HF 2000 Role of transforming growth factor beta in human disease. N Engl J Med 342:1350-1358

8. Johnson MD, Gold LI, Moses HL 1992 Evidence for transforming growth factor $\beta$ expression in human leptomeningeal cells and transforming growth factor $\beta$-like activity in human cerebrospinal fluid. Lab Invest 67:360-368

9. Massicotte EM, Del Bigio MR 1999 Human arachnoid villi response to subarachnoideal hemorrhage: possible relationship to chronic hydrocephalus. J Neurosurg 91:80-84

10. Kim RC, Talbert WM, Choe W, Choi BH 1989 Massive craniospinal collagen deposition after persistent postoperative intraventricular bleeding. Neurosurgery 24:771-775

11. Volpe JJ 2001 Intracranial hemorrhage: germinal matrix-intraventricular hemorrhage of the premature infant. In: Neurology of the Newborn. WB Saunders, Philadelphia, pp 428-493

12. Heep A, Stoffel-Wagner B, Soditt V, Aring C, Groneck P, Bartmann P 2002 Procollagen I C-propeptide in the cerebrospinal fluid of neonates with posthemorrhagic hydrocephalus. Arch Dis Child Fetal Neonatal Ed 87:F34-F36

13. Heep A, Stoffel-Wagner B, Bartmann P 2000 Procollagen propeptides in the cerebrospinal fluid of neonates with posthemorrhagic hydrocephalus (PHHC). Biol Neonate $78: 153$

14. Paneth N 1999 Classifying brain damage in preterm infants. J Pediatr 134:527-529

15. Levene MI 1981 Measurement of the growth of the lateral ventricles in preterm infants with real-time ultrasound. Arch Dis Child 56:900-904

16. Heep A, Engelskirchen R, Holschneider A, Groneck P 2001 Primary intervention for posthemorrhagic hydrocephalus in very low birthweight infants by ventriculostomy. Childs Nerv Syst 17:47-51

17. Segura I, Serrano A, Buitrago GG, Gonzales MA, Abad JL, Claveria C, Gomez L, Bernad A, Martinez AC, Riese HH 2002 Inhibition of programmed cell death impairs in vitro vascular-like structure formation and reduces in vivo angiogenesis. FASEB J $16: 833-841$

18. Flood C, Akinwunmi J, Lagord C, Daniel M, Berry M, Jackowski A, Logan A 2001 Transforming growth factor-betal in the cerebrospinal fluid of patients with subarachnoid hemorrhage: titers derived from exogenous and endogenous sources. J Cereb Blood Flow Metab 21:157-162

19. Kitizawa K, Tada T 1994 Elevation of transforming growth factor $\beta$-1 level in cerebrospinal fluid of patients with communicating hydrocephalus after subarachnoid hemorrhage. Stroke 25:1400-1404

20. Scheufler KM, Drevs J, van Velthoven V, Reusch P, Klisch J, Augustin HG, Zentner J, Marme D 2003 Implications of vascular endothelial growth factor, sFlt-1, and sTie-2 in plasma, serum and cerebrospinal fluid during cerebral ischemia in man. J Cereb Blood Flow Metab 23:99-110

21. Slevin M, Krupinski J, Slowik A, Kumar P, Szczudlik A, Gaffney J 2000 Serial measurement of vascular endothelial growth factor and transforming growth factorbeta 1 in serum of patients with acute ischemic stroke. Stroke 31:1863-1870

22. Ueberham U, Ueberham E, Gruschka H, Arendt T 2003 Connective tissue growth factor in Alzheimer's disease. Neuroscience 116:1-6

23. Tarkowski E, Issa R, Sjogren M, Wallin A, Blennow K, Tarkowski A, Kumar P 2002 Increased intrathecal levels of the angiogenic factors VEGF and TGF-beta in Alzheimer's disease and vascular dementia. Neurobiol Aging 23:237-243

24. Bocker-Meffert S, Rosenstiel P, Rohl C, Warneke N, Held-Feindt J, Sievers J, Lucius R 2002 Erythropoietin and VEGF promote neural outgrowth from retinal explants in postnatal rats. Invest Ophthalmol Vis Sci 43:2021-2026

25. Koehne P, Hochhaus F, Felderhoff-Mueser U, Ring-Mrozik E, Obladen M, Buhrer C 2002 Vascular endothelial growth factor and erythropoietin concentrations in cerebrospinal fluid of children with hydrocephalus. Childs Nerv Syst 18:137-141

26. Leviton A, Dammann O, O'Shea TM, Paneth N 2002 Adult stroke and perinatal brain damage: like grandparent, like grandchild? Neuropediatrics 33:281-287

27. Nakazato F, Tada T, Sekiguchi Y, Murakami K, Yanagisawa S, Tanaka Y, Hongo K 2002 Disturbed spatial learning of rats after intraventricular administration of transforming growth factor-beta 1 . Neurol Med Chir (Tokyo) 42:151-156

28. Moinuddin SM, Tada T 2000 Study of cerebrospinal fluid flow dynamics in TGF $\beta 1$ induced chronic hydrocephalic mice. Neurol Res 22:215-222

29. Ilzecka J, Stelmasiak Z, Dobosz B 2002 Transforming growth factor-beta 1 (TGFbeta 1) in patients with amyotrophic lateral sclerosis. Cytokine 20:239-243 
30. Rollnik JD, Sindern E, Schweppe C, Malin JP 1997 Biologically active TGF-beta 1 is increased in cerebrospinal fluid while it is reduced in serum in multiple sclerosis patients. Acta Neurol Scand 96:101-105

31. Zhu Y, Yang GY, Ahlemeyer B, Pang L, Che XM, Culmsee C, Klumpp S, Krieglstein J 2002 Transforming growth factor-beta 1 increases bad phosphorylation and protects neurons against damage. J Neurosci 15:3898-3909

32. Buisson A, Lesne S, Docagne F, Ali C, Nicole O, MacKenzie ET, Vivien D 2003 Transforming growth factor-beta and ischemic brain injury. Cell Mol Neurobio 23:539-550

33. Whitelaw A, Christie S, Pople I 1999 Transforming growth factor-beta 1: a possible signal molecule for posthemorrhagic hydrocephalus? Pediatr Res 46:576-580

34. Csuka E, Morganti-Kossmann MC, Lenzlinger PM, Joller H, Trentz O, Kossmann T 1999 IL-10 levels in cerebrospinal fluid and serum of patients with severe traumatic brain injury: relationship to IL-6, TNF-alpha, TGF-beta1 and blood-brain barrie function. J Neuroimmunol 101:211-221

35. Schromm AB, Brandenburg K, Loppnow H, Zähringer U, Rietschel ET, Carroll SF, Koch MH, Kusumoto S, Seydel U 1998 The charge of endotoxin molecules influences their conformation and IL-6-inducing capacity. J Immunol 161:5464-5471

36. Cai Z, Pan ZL, Pang Y, Evans OB, Rhodes PG 2000 Cytokine induction in fetal rat brains and brain injury in neonatal rats after maternal lipopolysaccharide administration. Pediatr Res 47:64-72

37. Cai Z, Pang Y, Lin S, Rhodes PG 2003 Differential roles of tumor necrosis factor-alpha and interleukin-1 beta in lipopolysaccharide-induced brain injury in the neonatal rat. Brain Res 13:37-47

38. Hagberg H, Gilland E, Bona E, Hanson LA, Hanin-Zoric M, Blennow M, Holst M, McRae A, Söder O 1996 Enhanced expression of interleukin (IL)-1 and IL-6 messenger RNA and bioactive protein after hypoxia-ischemia in neonatal rats. Pediatr Res 40:603-609

39. Stanimirovic D, Satoh K 2000 Inflammatory mediators of cerebral endothelium: a role of ischemic brain inflammation. Brain Pathol 10:113-126

40. Sävman K, Blennow M, Gustafson K, Tarkowski E, Hagberg H 1998 Cytokine response in the cerebrospinal fluid after birth asphyxia. Pediatr Res 43:746-751

41. Heep A, Schaller C, Rittmann N, Himbert U, Marklein G, Bartmann P 2004 Multiple brain abscesses in an extremely preterm infant: treatment surveillance with interleukin-6 in the CSF. Eur J Pediatr 163:44-45

42. Baumeister FA, Pohl-Koppe A, Hofer M, Kim JO, Weiss M 2000 IL-6 in CSF during ventriculitis in preterm infants with posthemorrhagic hydrocephalus. Infection 28:234-236

43. Xiao L, Li XQ, Zhang HX 2002 Effects of nao-yi-an granule on the intercellular expression of IL-6 in the experimental intracerebral hemorrhagic brain of rats. Hunan Yi Ke Da Xue Xue Bao 28:123-126

44. Takizawa T, Tada T, Kitazawa K, Tanaka Y, Hongo K, Kameko M, Uemura KI 2001 Inflammatory cytokine cascade released by leukocytes in cerebrospinal fluid after subarachnoid hemorrhage. Neurol Res 23:724-730

45. Bell MJ, Kochanek PM, Doughty LA, Carcillo JA, Adelson PD, Clark RS, Whalen MJ, DeKosky ST 1997 Comparison of the interleukin-6 and interleukin-10 response in children after severe traumatic brain injury or septic shock. Acta Neurochir Suppl (Wien) 70:96-97

46. Maskin B, Gammella D, Solari L, Videta W, Barboza MF, Geliz L, Rondina C 2001 Early release of the antiinflammatory cytokine IL-10 in traumatic brain injury. Medicina (B Aires) 61:573-576 